\title{
Water Resources and Irrigation Policy in Afghanistan: Ownership of Local Societies as a Key to Reconstruction
}

\author{
Kenji Nagata $^{1}$ \\ ${ }^{1}$ Senior Advisor, Japan International Cooperation Agency \\ Correspondence: Kenji Nagata, Japan International Cooperation Agency, Nibancho Center Building, 5-25, Niban-cho, \\ Chiyoda-ku, Tokyo 102-8012, Japan.
}

Received: February 11, 2016

Accepted: February 19, 2016

Available online: March 7, 2016

doi:10.11114/ijsss.v4i4.1359

URL: http://dx.doi.org/10.11114/ijsss.v4i4.1359

\begin{abstract}
Reconstruction assistance has been provided to Afghanistan over 14 years since 2002, but public security remains unstable. Afghan's rural areas, where more than $80 \%$ of the country's population lives, are characterized by the society which has an extremely strong sense of autonomy based on tribalism and warlords. Such agricultural village societies are important in recovery and reconstruction. Stable and sustainable agriculture through water resources development and irrigation holds the key to stabilize local societies. This study compares and analyzes the process and achievements of government/donor-led projects and community-oriented projects on water resources and irrigation. In the former projects, sustainability of irrigation facilities maintained by local societies has become a large issue, although they have contributed in rehabilitating irrigation areas. In the latter projects respecting local society, culture, tradition, religion, tribalism, politics and economics, many positive impacts are observed: farm household income increases, self-governing capacities of local societies are improved, public security is stabilized, and domestic and international refugees return home and settle. More specifically, this study proves community-oriented projects encourage Afghan local societies in recovery and reconstruction. Thus, existing principles and approaches in government/donor-led projects should be converted in to those under the initiative of local societies. Such a paradigm shift would work effectively for the recovery and reconstruction of Afghanistan, and develop the capacity and establish the ownership in the local societies.
\end{abstract}

Keywords: Afghanistan, policy, water resources, irrigation, ownership, capacity development, peace building

\section{Introduction}

\subsection{Background of the Present Study and Review of Previous Studies}

A lot of international conferences have been held since the Bonn Conference in 2001. In these conferences the Afghan Government has appealed for the recovery and reconstruction of Afghanistan with their ownership and leadership. The international community promises to assist the Afghan ownership with the partnership, and both parties have formally proclaimed many communiques that describe fundamental policy on the recovery, reconstruction and development for Afghanistan. The international community, encouraged by these communiques, has continued the assistance, and has poured tremendous resources into Afghanistan since 2002. Nevertheless, the development assistance appears not to succeed in Afghanistan, because people's livelihood in rural areas has not been improved enough and the national public security remains unstable.

Although Afghan people can elect the president and assembly members under the new election system arranged, Afghanistan virtually has no mechanism that the intention of the people or local societies is reflected in government policy. Government/donor-led projects may be carried out without recognizing local people's needs. It may diminish the ownership of local societies, and may constrain effectiveness, efficiency and sustainability of the projects.

Yutaka Hayashi (2014) examines possible peacebuilding in Afghanistan from the perspective of rural life after 2001. He explains that what people want is to make a better living, and suggests that there is a gap between those needs at the local level and international peacebuilding efforts at the national level. As the conclusion, he recommends that; 1) developmental and peacebuilding efforts should focus on the improvement of the economic situation, water and electricity in rural regions, 2) priority should be given to the perceptions and needs of the people, not to globally common knowledge and practices on good governance, and 3) both the international and governmental actors need to 
change the mindsets of peacebuilding, not based on the internationally and academically common understanding and practices of peacebuilding, but on the viewpoints of villagers and farmers to respond to the needs on the ground.

National Solidarity Programme (NSP), which is based on community-driven development (CDD) and was inaugurated in 2003, is structured around two major interventions at the village level; 1) establishment of gender-based community development councils (CDC) through a democratic election process, and 2) provision of "block grants", to a village maximum of USD 60,000 for projects designed by CDCs with a villagers' participatory approach. Andrew Beath, et al. (2013) summarize the results of the NSP impact evaluation (NSP-IE) as follows: 1) although utilities projects increased access to drinking water and electricity, and election procedures improved acceptance of democratic processes as well as female political and social participation, the impacts of NSP were more limited and sometimes negative; 2) NSP had no observed impact on crop yields and travel times after rehabilitation projects of irrigation canals and local roads, and also had a limited impact on objective economic outcomes such as household consumption, asset ownership or food insecurity; 3) despite the positive effects observed on appreciation of democratic norms, the institutional relevance of CDCs diminished significantly following project completion.

In the water resources and irrigation sector, new policies have been introduced after the establishment of "Interim Afghanistan National Development Strategy (I-ANDS)" in 2006. Those are, for example, "Water Resources Management Sector Strategy" established in 2008, the new "Water Law" enacted in 2009, and "River Basin Authorities" organized in 2011. The Afghan government, assisted by the World Bank, Asian Development Bank, European Commission, Japan International Cooperation Agency and others, has carried out water resources and irrigation projects, and has produced a substantial achievement to recover irrigation areas to 2.09 million hectares as of 2013. However, according to an interview on April 2015 with the directors of Ministry of Energy and Water, the problem has come to the surface that local communities have not implemented the operation and maintenance of the facilities well enough, and a question about sustainability of these projects has arisen recently.

Some studies have pointed out the issues on the reconstruction assistance in the water resources and irrigation sector of Afghanistan. Kai Wegerich (2009) suggests that there is a danger that externally funded projects, involving either construction of intakes or maintenance work, might weaken collective action within the canal communities or increase an already existing inequity in maintenance work requirements. He also suggests that the focus on water rights permits does not reflect the local reality and the water measurement technology in use, and the river basin councils (RBC) or water users' associations (WUAs) cannot solve local water problems. He argues that it might be more effective to focus on the special needs of individual canal communities and to work with the communities on rules that are locally needed and agreeable since it appears that the local system is still functioning in a traditional way. However, he also argues that rule enforcement has to be facilitated by the government. Vincent Thomas, et al. (2012) conduct a study on the Panj-Amu River Basin Program (PARBP) in north-eastern Afghanistan, which had been piloting the introduction of the "good" water governance concepts. Their analysis suggests that a strict application of the promoted policy models (i.e. decentralization and devolution of decision-making power to water users) may be counter-productive for water access in downstream areas, at least in the short term. As a conclusion, they argue that the pilot PARBP start working more closely with existing institutions on the resolution of practical problems related to water allocation rather than piling up more regulations.

The studies of Kai Wegerich (2009) and Vincent Thomas, et al. (2012) point out effectiveness and importance of the function of local societies. In order to develop local economy and promote peacebuilding, both studies and Yutaka Hayashi (2014) suggest that one would not easily introduce the existing methodology common to the international community, but should understand characteristics of local societies and utilize them into policies and projects. In addition, Yutaka Hayashi (2014) recommends for the government and donors to change the policy for the recovery and reconstruction of Afghanistan.

Now, a question arises as to whether these proposals are really effective or not. How can we utilize the local society power to rural development and state stability? What kind of the policy should the government and donors adopt? The previous studies proposed the significance of respecting local societies, but did not answer these questions. In order to put these proposals into practice for reconstruction assistance, it is necessary to verify their effectiveness.

\subsection{Purpose, Structure and Methodology of the Present Study}

In the development assistance to Afghanistan there is an important question: how should Afghanistan be recovered and reconstructed? The present study, from the view point of the water resources and irrigation sector, provides an answer to this fundamental question with the keywords of "strong sense of autonomy" and "ownership" of the local societies.

This study defines a local society with strong sense of autonomy as "a society that shares a sense of solidarity as a member of it, and that has function of autonomous decision-making and problem-solving, and that remains independent from the power of the state". The ownership of a local society is defined as "the will or the consciousness that a society 
or its members proactively and independently carry out a project".

The structure of the paper is as follows: after describing the background, purpose, structure and methodology of the study (Chapter 1), to understand Afghanistan's characteristics, significance and critical situation of the water resources and irrigation sector in Afghanistan are explained (Chapter 2), and the structure of Afghan local societies are clarified (Chapter 3); based on the results of a questionnaire, interviews and document investigations, the process and achievements of both government/donor-led projects and community-oriented projects are qualitatively compared and analyzed, and the technical, economic, social and comprehensive achievements of the community-oriented projects are identified, and the success factors are scrutinized (Chapter 4); through this analysis, an important policy on sustainable water resources and irrigation is recommended to contribute to the recovery and reconstruction (Chapter 5); at the end the conclusion and discussions are drawn (Chapter 6).

\section{Water Resources and Irrigation Sector in Afghanistan}

\subsection{Significance of the Water Resources and Irrigation Sector in Afghanistan}

Afghanistan's Gross Domestic Product (GDP), according to UN Data “Afghanistan” as of the year 2013, is USD 21,618 million and USD 708 per capita. Based on Central Statistics Organization, IRoA (2003-2014), the agricultural proportion of the GDP is decreasing from about $80 \%$ in the past to $52 \%$ in 2002 and $26 \%$ in 2013-14. The population of Afghanistan is 26.02 million (excluding 1.5 million of the nomad), and $76 \%$ live in rural areas and about $80 \%$ are said to be farmers. Thus, agriculture in Afghanistan, especially for the rural societies, is still highly important.

Afghanistan is located in an arid to semi-arid region. Annual precipitation in main agricultural zones, extending between EL. 500 to 2,000 m, is around 200 to $350 \mathrm{~mm}$ (the average from 1964 to 1973), most of which is concentrated in the winter season of November to April (JICA, 2011). Since rainfed agriculture in Afghanistan is unstable, irrigation water is more important than land and is decisive in the success or failure of agricultural outputs. Snowfall in high mountains is an important water resource in Afghanistan, and is melted in early spring, recharges groundwater, flows out and becomes river water. Afghan people can survive by using the water for farmland through constructing wells, karezes, water intake facilities and irrigation canals. Water, in fact, is the lifeline to control agricultural production in Afghanistan.

Afghan people count not on the central or local government but on rural or tribal communities, and warlords support and control their lives. Mohammad Naghizadeh (2004) explains that warlords provide local people with employment opportunities, and when demobilizing them, only the agriculture sector, for the meantime, can create employment opportunities instead of warlords. K. Mushakoji (2004) also indicates that the recovery of agricultural communities is important in securing employment and income as well as facilitating disarmament and repatriation of refugees who remain in cities. That is to say, the agriculture sector is extremely important for the recovery and reconstruction of Afghanistan. The sector of water resources development and irrigation, especially, is the key to the agricultural development, and is a major sector that can contribute toward increasing and stabilizing agricultural products and facilitating better public security in rural societies.

\subsection{Present Conditions and Crisis of Water Resources and Irrigation Sector}

In 1978 when struggles were about to start, Afghanistan was self-sufficient in grain. It had 7.70 million hectares of agricultural land, of which 3.00 million hectares (39\%) were irrigated. As of 2013, 3.61 million hectares are cultivated, of which 2.09 million hectares (58\%) are irrigated but 1.52 million hectares (42\%) are rain-fed cultivation and depend on natural rainfall (Central Statistics Organization, IRoA, 2003-2014). Thus, when drought comes, agricultural crops such as rice, wheat and root crops cannot be produced enough for people to survive.

The Afghanistan Times reported that Afghanistan had experienced 8 (eight) times of drought in 12 years from 2000 to 2011. B.J.M Goes, et al. (2015) show discharge data in the Helmand River, which proves that the recent average discharge from 1999 to 2012 is only $61 \%$ of the overall average from 1952 to 2012, and is equivalent to a 5-year drought discharge. The drought in 2000 was the worst in the last 30 years, and further deteriorated a food supply that had been in crisis by the war. The Afghanistan Times also reported that the drought in 2000 would incur almost no crops in the north rainfed agriculture, and would have a great impact on agricultural production in the central highland, and consequently would cause serious damages to 3 or 4 million people. It also reported that the 2011 drought would result in almost no production in $80 \%$ of rain-fed agriculture lands in drought-affected areas, where famine might strike 2.6 million people equivalent to $10 \%$ of the country population.

Few crops or famine is mainly caused by "rain-fed agriculture" that is fragile and unstable against drought. It is obvious that such drought or famine exhausts and collapses rural communities, expands local conflicts, and facilitates distrust in the government. Stable agriculture in rural areas is the indispensable prerequisite for stable national security. It is most precious to the present Afghanistan that local people can go through their lives with dignity when they ordinarily work. 
It must largely contribute toward regional security and stability.

\subsection{Impacts on Agriculture by Wars and Droughts}

More than 20 years wars since 1978 had destroyed the agricultural infrastructure, and had forced rural people to leave villages to be domestic or international refugees. Water resources and irrigation facilities were damaged, and the operation and their maintenance were disrupted. As one misfortune followed another, severe droughts have continued to attack Afghanistan since 2000. According to statistical data in the Central Statistics Organization of IRoA (2003 to 2013-14), FAO (2002 \& 2012) and UNDP/FAO (1981), prolonged wars and frequent droughts had following severe impacts on agriculture:

As of 2013, Afghanistan's land area is $652,230 \mathrm{~km}^{2}$, of which $12 \%$ is arable, $3 \%$ is forest, $46 \%$ is pasture, and the remaining 39\% is mountainous and other land. Arable land consists of irrigated areas, rainfed areas and fallow land. The arable land in Afghanistan stays constant about 8 million hectares since 1980s. The irrigated area changes as annual snow accumulation and precipitation because there are many karezes and direct intakes from rivers. However, the irrigation area declined from 2.59 million hectares (32\% of the arable land) in 1980s to 1.75 million hectares (22\%) in 2002. Furthermore, JICA (2002) reported that the actual irrigation area in 2002 was presumed to be between 1.2 and 1.3 million hectares. The irrigation area had improved to 2.09 million hectares by 2013, but is still less than the area in 1980s. Rainfed agricultural area, which has drastically changed due to annual precipitation and wars, fluctuated from 0.4 to 1.5 million hectares between 1980s and 2013. The least rainfed agricultural area was 0.432 million hectares in the severest drought year of 2000. In addition, the rainfed agricultural areas in the drought years of 2008 and 2011 were 1.15 and 1.16 million hectares, decreasing by $20-40 \%$ comparing with the areas in the years before and after 2008 and 2011. The proportion of fallow land in the arable land was kept between $49-54 \%$ in 1980 s, but was increased to $65-70 \%$ (66\% on average) after 1990 while civil conflict was escalating. The highest rate of $72 \%$ was recorded in 2002. Fallow land rate after 2003 transitioned from $51 \%$ to $62 \%$ (56\% on average).

\section{Structure of Local Society in Afghanistan}

\subsection{Characteristics of Local Society - Agricultural Society, Tribe and Warlords}

The structure of the local society in Afghanistan is complicated and difficult to understand, and is generally less well-known. Main characteristics of the Afghan local society are to be "agricultural village society". Although the agriculture portion of GDP has been decreasing, agriculture is still an enormously important industry in Afghanistan as $80 \%$ of the country's population are farmers. According to Yoshio Endo (2004), each village forms an economic unit with a principle of self-sufficiency, and secures strong autonomy and independence as a social unit based on mutual cooperation of Islam. One more characteristic to strengthen the cohesion is tribalism. The independence of local societies based on tribalism has both advantages and disadvantages; demonstrating strong resilience against external pressure and prolonging struggles to neighboring villages. In addition, tribalism gives relief and orientation inside a local society, though it is recognized as an obstacle to recovery and reconstruction as well as law and order.

Another matter closely relating to ethnic and tribal issues is the existence of warlords. According to Takeshi Daimon (2003), warlords have been in Afghanistan since the formation of the country in 1747, and have been a part of Afghanistan's "culture" or "custom". Warlords provide employment opportunity serving as a soldier for local people who were deprived of means of living due to civil war or severe droughts.

\subsection{Representativeness of Local Society}

The smallest administrative unit of the Afghanistan government is a district, under which villages or "qaria" exist as autonomous bodies. Village chiefs deal with the government administration as representatives of the villages. "Jirga" in Pashto or "Shura" in Arabic, which is a council based on traditional customary laws named "Pashtunwali", plays an important role in Pashtun villages. In addition, National Solidarity Program (NSP) implemented by the Ministry of Rural Rehabilitation and Development has established Community Development Councils (CDC) and Clustered CDCs (CCDC) consisting of 3 to 5 CDCs. Thus, the present Afghanistan is in the situation where traditional villages and newly-established CDCs coexist in the rural administration.

Raphy Favre (2005) clarified the characteristics and representativeness of an Afghan society as follows: Afghan society is structured in "qawm" or "networks" with a sense of villages" solidarity. Since "qawm" has no definitive territory and resulted in a poor socio-political representation of its members, it has prevented the central government to promote modernization. However, "qawm" has been a crucial "social capital" of the resilience to external shocks for the Afghan society. The "qawm", of which geographical boundary had been clarified during wars, has been transformed into "manteqa" or a "place where a person is originating/living". This "manteqa" is an important part that forms individual identity and local solidarity in Afghans. This is the state of the present Afghan society, and "manteqa" actually represents a territorial and social unit in Afghanistan's local areas. The total number of "manteqa" is probably 3,000 to 
4,000 , which is far easier to support than 20,000 to 40,000 villages.

As history proves, therefore, it may be difficult to introduce "democratic society" without careful consideration into Afghan rural societies that have strong sense of cohesion and autonomy. It seems to be necessary to recover and reconstruct Afghanistan appropriately taking advantages of Afghan societies.

\subsection{Land Ownership and Water Allocation in Local Society}

Afghan local society is a community centering on agriculture. Farmers can be divided into three hierarchies, such as a land owner, a farmer with land, and a peasant or laborer. Rural people without land become migrant workers or work in communities as peasants or farmhands. Since warlords have gained power and controlled land during the civil war, numbers of farmers with land have decreased in recent years. Mohammad Naghizadeh (2004) introduced the survey results that most or half of rural people have no land. Land ownership and water allocation are large issues for the recovery of rural societies. To comprehensively address issues on land and water, the government established the Supreme Council on Land and Water (SCoLW) designated by Presidential Decree in 2014, adding "Land" to Supreme Council on Water (SCoW) stipulated in the new Water Law.

The "mirab" system exists in Afghanistan. According to the report of Expedition to South West Hindukush, University of Tokyo (1969), the two kinds of specialists called "mirab" and "khadadar" manage water allocation in villages even today. The "mirab" is a water manager who has responsibility for water diversion from a river to a village, and the "khadadar" is an assistant water manager who divides water inside a village after "mirab" secures water from a river. Social status of "mirab" is firm in principle as a specialist independent from village hierarchy. A professional fee to the "mirab" is paid as a duty by all the people (including peasants) who cultivate and are responsible for farm land.

\section{Comparative Analysis between Government/Donor-led Project and Community-oriented Project}

\subsection{Overview of Government/Donor-led Project and Community-oriented Project}

"Government/donor-led projects" on water resources and irrigation have been restoring irrigation areas in Afghanistan, but inappropriate operation and maintenance of the facilities has become a significant issue. Irrigation associations (IA) or water users associations (WUA) that the projects have formulated do not function well in many cases. The government/donors might be overhasty in accelerating the recovery. As a consequence, IAs or WUAs and local people might have little ownership in the irrigation networks, and might not manage the facilities by themselves. Behind these cases, there is a circumstance that government/donor-led projects make great use of concrete works which are difficult for local people to maintain. Such situations disturb expansion of irrigation areas, and increases $\mathrm{O} \& \mathrm{M}$ costs spent by the government. Furthermore, those situations might accelerate the collapse of autonomous control in local societies.

Peace [Japan] Medical Service (PMS) has implemented "Community-oriented projects" on water resources and irrigation in the eastern provinces. It respects local society, culture, tradition, religion, tribalism, politics and economics. PMS is a local non-governmental organization (NGO) that operates medical services and irrigation projects. It has been supported by a Japanese international NGO namely "Peshawar-kai", whose Home Page explains that it was established in 1983 and has helped Dr. Tetsu Nakamura's activities of medical services and irrigation projects in Pakistan and Afghanistan. Dr. Tetsu Nakamura is the representative of "Peshawar-kai" in Afghanistan. He and PMS started the Marwarid Canal Irrigation Project with $25 \mathrm{~km}$ in total length in the downstream of Knar River in east Afghanistan in March 2002, and successfully completed it in February 2010. In this project area, the irrigation facilities are well maintained by PMS and local people, and farm income has increased. Public security has become stable, and repatriated refugees have settled. PMS and "Peshawar-kai" have successively implemented the comprehensive village recovery project namely "Green Ground Fund for Afghanistan Programme". The Japan International Cooperation Agency (JICA) has supported a part of it since 2011.

\subsection{Achievements and Challenges of Government/Donor-led Project and Community-oriented Project}

Achievements and challenges of both projects on water resources and irrigation are compared and analyzed, focusing on community-oriented projects implemented by PMS, and referring to government/donor-led projects. Technical, economic and social achievements are identified as the direct outcomes through the projects. These three achievements are closely related and produce larger accomplishments with a synergetic effect of the three. Thus, these are verified as comprehensive achievements.

\subsubsection{Technical Achievements: Developing and Introducing Appropriate Civil Engineering Technology}

Modern civil engineering technology on flood management and water utilization makes great use of concrete structures, which are generally strong, but at the same time brittle with no flexibility when receiving unexpected external forces such as a large flood or sediment disaster. Thus, their maintenance is imperative. However, local people have difficulty in maintaining concrete structures, which need a large amount of costs and sophisticated technology in their 
construction, especially in large rivers. Government/donor-led projects basically apply modern civil engineering technology to carry out flood management and water utilization projects.

On the other hand, PMS had exercised its ingenuity in creating various simple civil engineering technologies suitable for Afghanistan, and has introduced those technologies into their projects. PMS's basic policy is: 1) to enable stable water intake in times of drought or flood, 2) to resist heavy floods in large rivers, 3) to be simple enough for local people to carry out the operation, maintenance and repair, and 4) to keep project costs reasonable. Consequently, concrete structures were utilized as less as possible. Instead of concrete, gigantic stones and round stones are used to construct firm structures, because stone material is easy to collect in Afghanistan and Afghan people are good at dealing with stones. The technologies applied by PMS's community-oriented projects on water resources and irrigation are shown as follows:

1) Oblique weir with large boulders. This weir, with affordable cost and good workability in construction, enables stable water intake throughout the year;

2) Spur dikes, foot protection and revetment works with gigantic stones and gabion works. These measures of riverbed and riverbank slope sufficiently resist heavy floods in large rivers;

3) Dual intake-gates with flashboards, steep-gradient canals, and sand basins with a water conveyance gate and a drain gate. This system reduces sediment inflow to the canal and enables easy dredging of deposited sand;

4) Canals with gabion works, willow works, soil embankment and soil-cement lining on canal beds;

5) Reasonable project costs. As shown in Table 1, comparing project costs between government/donor-led projects and PMS's community-oriented projects on water resources and irrigation, the latter for new development lies approximately at the lower end of the former, and the latter for improvement is fairly lower than the former.

Table 1. Project Costs of New Development and Improvement on Water Resources and Irrigation

\begin{tabular}{lcc}
\hline Project Cost & Government/donor-led Projects & Community-oriented Projects by PMS \\
\hline $\begin{array}{l}\text { for new } \\
\text { development }\end{array}$ & $\begin{array}{c}\text { from USD 5,000 to 10,000 per hectare } \\
\text { (USD 7,000 to 8,000 per hectare on median) }\end{array}$ & $\begin{array}{c}\text { USD 4,832 per hectare } \\
\text { (Marwarid Weir and Canal Project) }\end{array}$ \\
\hline $\begin{array}{l}\text { for } \\
\text { improvement }\end{array}$ & from USD 2,000 to 2,500 per hectare & from USD 130 to 2,000 per hectare \\
(only as a guide) & (USD 685 per hectare on average)
\end{tabular}

Description: The costs of government/donor-led projects were obtained from an interview with the director of Water Program in Ministry of Energy and Water (MEW) in Afghanistan on April 2015. The costs of community-oriented projects by PMS are summarized referring to the written material given by Dr. Tetsu Nakamura (PMS) in 2015.

\subsubsection{Economic Achievements: Improvement of Livelihood of Local People}

Government/donor-led projects on water resources and irrigation are recognized to achieve the economic impacts when they completed the planned facilities and started delivering the given water amount to farms. The projects are commonly subcontracted to constructors. The construction work itself also contributes to the local economy, normally employing local people as unskilled laborers although engineers and skilled workers are not from local societies.

In community-oriented projects by PMS, many local people and repatriated refugees worked on almost all the construction activities as not only as unskilled laborers but also skilled technicians (Dr. Tetsu Nakamura, 2015). Consequently, their incomes are increasing. According to the questionnaire investigation in JICA (2015), $11 \%$ of the respondents answered that they had been working in PMS projects, and 58\% said irrigated farms increased, and 80\% replied that enough water was supplied. Additionally, $80 \%$ replied that they were satisfied with increasing farm products and incomes because plentiful irrigation water enabled to harvest twice a year, introducing not only wheat and corn but also various crops such as rice and vegetables owing to acquiring agricultural knowledge through farming trainings. Moreover, $77 \%$ answered that positive changes had arrived in their lives.

These investigation results indicate that the community-oriented projects bring a lot of benefits to the local people; a stable supply of irrigation water, increased irrigation areas, a rise in agricultural productivity, surplus production and increased income. Furthermore, it can be assumed that the local agriculture became self-sustainable, the local population increased, employment opportunities in agriculture increased, and, finally local economies were activated.

\subsubsection{Social Achievements: Capacity Development of Local People on Operation and Maintenance}

The new Water Law encourages the establishment of water users' associations (WUA) or irrigation associations (IA), which are expected to carry on the operation and maintenance $(\mathrm{O} \& \mathrm{M})$ of the facilities. Water resources and irrigation engineers play a role to formulate them in many government/donor-led projects. As the Directors of Ministry of Energy 
and Water (2012-2014) pointed out, however, that the $\mathrm{O} \& \mathrm{M}$ by local people is not necessarily successful because they became dependent on the government, and the associations (IAs and WUAs) formulated in the projects became non-functional following project completion.

On the other hand, in community-oriented projects by PMS, local people were not only directly involved in the projects, but also gained technical comprehension and capabilities of the projects through capacity development trainings. Consequently they had become important leaders in charge of O \& M. The questionnaire investigation in JICA (2015) shows that $71 \%$ of respondents who had worked in PMS's projects said they may teach their acquired know-how to others. It may be an indicator of their confidence in technology learned and their voluntary will to contribute to local societies.

PMS applies the policy to continue $\mathrm{O} \& \mathrm{M}$ for five years after construction of irrigation facilities, and then to transfer control to local people and societies. During the first five years, PMS respects and monitors the rulemaking process by local societies for $\mathrm{O} \& \mathrm{M}$, and supports local people to carry on $\mathrm{O} \& \mathrm{M}$ through additional construction work. The questionnaire investigation in JICA (2015) confirms that $94 \%$ of the respondents replied that the mirab system is well-functioning and $70 \%$ answered to pay a professional fee to mirabs. To the question of who should be responsible for O \& M, 64\% selected Community Development Council (CDC) or District Development Assembly (DDA) and 36\% replies PMS only. This indicates that the local societies are formulating a water management system that $\mathrm{O} \& \mathrm{M}$ is implemented by WUA or IA centering on mirabs, which are supported by CDC or DDA or "Shura".

In fact, ownership by local people is extremely important for them to carry on $\mathrm{O} \& \mathrm{M}$ of facilities in a sustainable manner. The questionnaire investigation in JICA (2015) shows that $37 \%$ of the respondents answered that they had attended meetings for canal maintenance more than five times, and $80 \%$ replied that they had participated in cleaning once to quater a year. This indicates that the community-oriented projects by PMS had developed ownership by local people for water resources and irrigation facilities.

\subsubsection{Comprehensive Achievements: Stabilization of Local Society}

The community-oriented projects by PMS produced the economic achievements of increased farm household incomes based on the technical achievements of stable irrigation water use, and accomplished social achievements in developing the capacity of local societies and developing ownership by local people for water resources and irrigation facilities.

Referring to the questionnaire investigation in JICA (2015), 87\% of the respondents replied that local people helped each other in canal cleaning and farming, and $93 \%$ replied that the relationship among local people had improved and $84 \%$ replied that security conditions were better. $42 \%$ and $36 \%$ of the respondents used to be refugees replied that they had evacuated for more than 20 years and 11 to 15 years respectively. This answer suggested that refugees over many years return home. As seen above, community-oriented projects by PMS have various positive impacts on local societies. They are summarized as comprehensive achievements and include:

1) Autonomous control systems in local societies are formulated and maintained. Irrigation networks and the riverine intake systems are lifelines that tie Afghan rural communities and strengthen the solidarity of rural communities. Stable irrigation water supply contributes to stabilized local societies with the cohesion of water sharing (Tetsu Nakamura, 2014).

2) Public security stabilizes. Water conflicts disappear and farmers are able to support themselves with their own farm production. Such self-sufficiency contributes to stable public security.

3) International and domestic refugees return home and settle.

4) The local environment improves and local people's health benefited through the projects outcomes; sand defense forests, green irrigation farms, and decline of local temperature by the forests and greens.

\subsection{Factor Analysis of Success of Community-oriented Project}

The comparative analysis described above found that community-oriented projects accomplished a great achievement including a lot of splendid values. Dr. Tetsu Nakamura's unyielding spirit and charisma enabled the projects to continue and succeed, and won the trust of local people in difficult social and political situations. Nevertheless, it is also obvious that the success was supported by the various civil engineering technologies and the project process which PMS developed and introduced. To disseminate the fruits of such great success, it is necessary not only to laud the success as a great personal accomplishment, but also to transfer the successful technologies, processes and approaches to the power of organizations. To do so, this study found through the above analysis that it is especially significant to consider the following success factors in implementing water resources and irrigation projects:

1) Full understanding of local societies. In addition to investigating natural conditions including flood damages and water utilization details, social conditions in local societies should be deeply understood such as local society, 
culture, tradition, religion, tribalism, politics and economics. The full understanding of local societies enables proper decision-making and provides project practitioners with the criteria for making a technical or social judgement about planning and implementing water resources and irrigation projects.

2) Mutual trust based on the community-oriented policy. Adopting a hands-on/pragmatic approach, community-oriented projects were carried out from the view point of local people, respecting the local culture and philosophy and working for local communities. The projects, based on their continuous implementation and accumulated accomplishments, could gain acceptance and trust from the local societies and their members, the influential people, the "shura" and the district and provincial governments. Then, local societies cooperate on the projects because they are beneficial.

3) Community-oriented construction work. PMS has carried out community-oriented projects, hiring necessary skilled and unskilled workers from local societies for construction work. In Afghanistan, not only PMS, but also CDCs or local companies undertake and implement many small projects, and take the similar approach as PMS. Such construction systems may be called as "community construction system (CCS)", and have a lot of advantages. As an example, local societies or similar bodies can solve problems and conflicts, including security enforcement, with their autonomous control based on the territorial or tribal cohesion. These activities about construction and local governance encourage local people and societies to develop their capacity.

4) Enhancement of the awareness and methodology for O \& M. Community-oriented projects provided facilities enabling local societies to carry out their $\mathrm{O} \& \mathrm{M}$. The projects applied the cycle of design, construction, monitoring and improvement as a construction work process, sometimes learning by trial and error, and quickly dealt with problems such as flood erosions. Such continuous process helps construct facilities suitable to sites and communities, and enhances the awareness and methodology for $\mathrm{O} \& \mathrm{M}$ in local societies.

5) Fostering ownership by local societies through the developing capacity. Community-oriented projects developed local human resources not only as unskilled laborers but also as skilled hands or technicians, adding modern technology to traditional techniques. Afghan people have many experiences and skills in improving karezes and small canals. Many of them live in their home area, and are expected to be human resources who ongoingly contribute to the $\mathrm{O} \& \mathrm{M}$ of facilities. This generates various advantages; utilization of cheap labor forces, economic stability of local societies, raising local people's incentive for farming, capacity enhancement for entire villages. Developing local human resources make a huge contribution to activating local societies and enhancing their ownership.

6) Teamwork power is bolstering projects. Project members as well as local people and "shura" made hard efforts as a team to obtain water indispensable to local societies. Additionally, local and central governments support the projects and play their roles to carry forward projects. This is a power of teamwork and a fundamental drive to perform difficult jobs.

\section{Policy on Sustainable Water Resources and Irrigation to Contribute to Recovery and Reconstruction}

\subsection{Sustainable Development in Local Societies through Fostering the Ownership}

Expanding irrigation agriculture based on water resources development is a high-priority issue for stable farm production since Afghanistan is located in an arid or semi-arid region. Water resources development is technically planned and implemented, but should be advanced to think through social aspects of water resources utilization and $\mathrm{O}$ \& M. Especially in Afghanistan where water is precious and necessary for people to sustain life, the activity of successfully developing, utilizing and maintaining water resources is equivalent to forming a proper and sustainable social system.

Afghan local society is characterized as agricultural society based on tribalism and warlords, and has a strong autonomous sense. Water resources and irrigation projects are affected by the characteristics of the local society, and also give impacts to the local society. Therefore, local societies should not "accept," but proactively implement a project with their own initiative, and consequently secure sustainable development. It is extremely important that local societies develop their own capacity and establish strong ownership for an outcome of the projects. The development of the capacity and ownership inspires local societies to stabilize economic and political situations, and leads the country to recovery and reconstruction. Moreover, community-oriented projects provide water, a green and calm environment, and keep people healthy especially for women and children to restore their natural energy.

\subsection{To Foster the Ownership of Local Societies}

\subsubsection{Use Functioning System and the Ability of Local Society}

At the beginning of reconstruction assistance in Afghanistan, strict rules remained in local societies rooted in their 
culture, tradition and religion; although no modern governing system existed. People have survived the war-torn era together within family, lineage, village and society. Water allocation rules had been historically formulated in rural societies, where "mirabs," who observe the rules as water manager, can be found even now in all provinces. In addition, Yoshio Endo (2004) introduced results of a survey at the beginning of reconstruction that a part of the former local administration systems firmly remained. Presently, old and new autonomous control bodies have been formed in rural areas.

The international community might ignore existing local rules and abilities, and introduce rules based on a Western sense of worth, and start reconstruction of Afghanistan toward a democratic country. However, Afghanistan's local societies, with a strong autonomy, have been averse to the Western value and reluctant to cooperate, and do not foster ownership. Alternatively, donors may have thought that traditional societies, if they remain, would enhance the risks of conflicts, corruption and warlords.

However, the following conclusion can be derived from the comparative analysis in this study: to reconstruct Afghanistan, the modern law common to the international community should not be forced, but the customary laws rooted deeply in local societies should be applied to Afghanistan; firstly the country must be stabilized so that people are able to live when they ordinarily work; after doing so and obtaining the people's trust, Afghanistan could be transformed gradually to a country with democratic governance under modern law.

\subsubsection{Understand Characteristics of Local Society}

In order to reconstruct Afghanistan making use of existing customary laws, assistance project practitioners have to understand the characteristics of local societies and analyze the stakeholders. Impacts that a project will make must be carefully evaluated. Whether or not local people can actively engage in development projects with their ownership depends on the level of comprehension in local societies, and also depends on more stakeholders accepting the development and reaching consensus.

Validity of the approach to reflect local knowledge and experiences, such as participatory development, community participation and stakeholders' meetings, is already acknowledged. Many donor projects adopt the participatory approach. Meaningful participation by all stakeholders is needed. However, many projects might misuse the participatory approach as "pardon". Thus, the participatory approach that has been taken in Afghanistan should be improved. Local knowledge (LK) and traditional knowledge (TK) should be recognized not only as knowledge bases, but as local society or culture, and should be leveraged as parts of recovery and reconstruction.

\subsubsection{Strengthen the Governance Capacity of Local Society}

Capacity enhancement of local people and communities is important and imperative to consolidate the ownership of development by local societies. Water resources and irrigation projects usually include capacity development activities for IAs or WUAs, which can contribute to developing governance capacity by local society.

Capacity of the local societies in Afghanistan has been strengthened mainly through the National Solidarity Program (NSP). NSP established new local organizations, namely community development councils (CDC) through democratic election processes, and has enhanced the capacity of CDCs, avoiding focusing on the governance by existing local societies. While more than 12 years have passed since the commencement of NSP, Andrew Beath, et al. (2013) report that the institutional relevance of CDCs diminishes significantly following project completion. The directors of Ministry of Energy and Water (2012-2014) suggest that various situations have been created in local areas. For example, some CDCs have been empowered to become representatives of local communities, and some CDCs have been well-organized and integrated with existing authorities, and some CDCs have functioned as the same as the existing system under warlords. There are various kinds of local societies that are functioning as effective local representatives under the present regime. Whatever those are, development projects should accept them as the counterparts or stakeholders, and cooperate with them.

\subsection{To Widely Disseminate Sustainable Water Resources and Irrigation Projects}

The community-oriented water resources and irrigation projects have superior technical, economic and social aspects, and can also contribute to peace building in Afghanistan under conflict-affected conditions. Such projects are worthy of being disseminated as a model of success. To do so, not only NGOs but also the government must introduce the policy and approach of the community-oriented project into government/donor-led projects. The government and donors are requested to reverse their way of thinking. They need to change their viewpoint on the recovery and reconstruction from the quick impact to the community-oriented model that encourages self-reliant development and the stability of local societies. It is of absolute importance to organize water resources and irrigation projects "of the people, by the people and for the people".

The national government in a fragile country like Afghanistan is not established enough and is difficult to perceive the 
needs of local people. Paradoxically, however, the government should promote development for the local people and societies who sustain the country, and should encourage self-reliance by local societies. It is crucial that the government introduce the community-oriented policy and process, which is expected to foster trust by local people and societies in the government. This process seems to be the time needed to direct the country to stabilization from instability. The development rooted in Afghanistan society and culture must be the policy of recovery and reconstruction that the government should take, and must be the assistance policy the donors adopt.

\section{Conclusion and Discussion}

The present study, through the comparative analysis of water resources and irrigation projects in Afghanistan, shows that a community-oriented project increases farm household income, encourages local societies to activate their autonomous control system, stabilizes local public security and makes refugees return home and settle. In other words, this research clarifies that the community-oriented project, which respects local society, culture, tradition, religion, tribalism, politics and economics, contributes to recovery and reconstruction in local societies in Afghanistan. The results from this study indicate that raising ownership and capacity is effective for the restoration of Afghan local societies with strong autonomy. Therefore, it is recommended that the government and donors should change their philosophy and methodology for the recovery and reconstruction of Afghanistan from a government/donor-led to a community-oriented approach.

Both Kai Wegerich (2009) and Vincent Thomas, et al. (2012) suggest using the characteristics and power of local societies for the improvement of rural water issues. This study verifies its effectiveness and demonstrated that it could contribute to rural development. Yutaka Hayashi (2014) recommends that the government and donors place priority on the perceptions and needs of the local people, and change the mindsets on peacebuilding. The present study confirms that a community-oriented project could contribute to peacebuilding through improving local irrigation water supply, and verifies that such policy change works effectively toward recovery, reconstruction and development in Afghanistan.

Haruyuki Shimada (2013) refers to many opinions that the assistance based on "Liberal Peace Building" made troubles and is a cause of destabilization in the past peace building activities. He questions whether Afghanistan would be another case of failure as it has been making reconstruction efforts according to the concept on which the Western societies are based. Roland Paris and Timothy D. Sisk (2009) describe that one of the five contradictions in peace building is "local problem resolution by universal values". Mohammad Naghizadeh (2004) describes that Afghanistan, in the long history, had not achieved self-sustained economic growth and societal development. He suggests that the reason why not is for Afghanistan to have introduced the social science framework (especially economics) formed on the model of Western successes, and therefore not to have focused on the patterns of the human economic behavior and relation of mutual trust as the custom inherent in Afghanistan. Raphy Favre (2005) proposes that the "manteqa" should represent the administration at the district level when development projects require fair representative bodies/parties at the site. The "manteqa" reflects reality of the structure in local societies, and its territory is almost coincident with small basins and natural landmarks.

The community-oriented project introduced in this study is completely different from a project that enforces the rules "freedom and democracy" of the international community. It respects the culture and structure of local societies as much as possible, and is a successful example of introducing modern technology to traditional techniques. It is a small success but would be an "answer" to the Haruyuki Shimada's question, Roland Paris's contradiction, the Mohammad Naghizadeh's expostulation, and Raphy Favre's proposal. It suggests a future direction to tackle the recovery and reconstruction for Afghanistan.

The present study may encounter criticism that if the local culture and governing system would be utilized in assistance projects, existing bad customs such as corruption, warlords and conflicts may remain and fix, and may become difficult to recover the local system to a "proper" direction of establishing a democratic society. Nevertheless, in conflict-affected countries like Afghanistan, the most urgent issue is for local people to survive and have untroubled living conditions and stable public security. It is important for local people to be able to live with dignity when they ordinarily work even if the way like this would be a detour. It is also necessary to plan a timeline to stabilize the country in the short term through applying customary laws, and to step out in the direction of modern law and order and democratization in the middle and long term.

\section{References}

Afghanistan Times: Referred from the articles in Nov. to Dec. of 2011.

Beath, A., Christia, F., \& Enikolopov, R. (2013). The National Solidarity Programme: Assessing the effects of community-driven development in Afghanistan. WIDER Working Paper No. 2013/112, United Nations University, October 2013. 
Central Statistics Organization of Islamic Republic of Afghanistan (2003-2014). Afghanistan Statistical Yearbooks from 2003 to 2013-14.: the proportion of the GDP is $26 \%$ in agriculture of cereals, fruits, dry fruits, livestock and others, $20 \%$ in industry of mining and quarrying, manufacturing, electricity/gas/water and construction, and 54\% in services.

Directors of Ministry of Energy and Water (2012-2014): Obtained from the interviews to the director of Water Program as well as the director general of Water Resources in Ministry of Energy and Water in Afghanistan (MEW) during the author's assignment in MEW during 2011-2014.

Expedition to South West Hindukush, University of Tokyo (1969). Water and Village Life in East Afghanistan 1967. (pp41-47). University of Tokyo Press: The research was carried out in Logar and Parwan provinces in Afghanistan from June to September 1967, setting the study theme of "Water in Arid Region". The present situations still remains as almost same as ones in 1960s.

FAO (2002 \& 2012). Provincial Landcover Atlas of Islamic State of Afghanistan 2002 and 2012.

Goes, B. J. M., Howarth, S. E., Wardlaw, R. B., Hancock, I. R., \& Parajuli, U. N. (2015). Integrated water resources management in an insecure river basin: a case study of Helmand River Basin, Afghanistan. International Journal of Water Resources Development, 2015.

Haruyuki, S. (2013). Gendai-Afuganisutan-Shi: Kokka-Kensetsu-no-Mujun-to-Kanousei [Modern History of Afghanistan: Contradictions and Possibilities of Nation Building] (pp14-15). Akashi Shoten: "National reconstruction", which was promoted on the fundamental basis of values of democracy, rule of law, introduction of market-oriented economy, etc., is called as "Liberal Peace Building" by Roland Paris and others.

JICA - Japan International Cooperation Agency (2002). Project Formulation Survey in Afghanistan: Chapter 9 Agriculture and its infrastructure (pp5). March 15 ${ }^{\text {th }}, 2002$.

JICA - Japan International Cooperation Agency (2011). Needs Assessment Survey for Water Resource Management and Development in Afghanistan FINAL REPORT, August 2011.

JICA - Japan International Cooperation Agency (2015). Evaluation of Rehabilitation of Irrigation Systems and Baseline Survey of Meeran in Nangarhar, Draft Final Report, April 2015: Questionnaire survey was carried out to 287 households in Behsud, Kuz-Kunar and Kama districts of Nangarhar Province.

K. Mushakoji (2004). Afuganisutan-no-Kokka-Saiken-to-Fukkou-Kaihatsu-heno-Teigen [Recommendations to National Reconstruction and Recovery Development in Afghanistan]; Afuganisutan: Saiken-to-Fukkou-heno-Chousen [Afghanistan: Challenges to Reconstruction and Recovery] (viii). Written and edited by K. Mushakoji and Y. Endo. Nihon Keizai Hyouronsha Ltd.

Kai Wegerich (2009). Water Strategy Meets Local Reality. Afghanistan Research and Evaluation Unit (AREU), Issues Paper Series, April 2009.

Mohammad, N. (2004). Chapter 6 Afuganisutan-no-Fukkou-to-Nogyou-no-Yakuwari [Afghanistan Recovery and the Role of Agriculture]; Afuganisutan: Saiken-to-Fukkou-heno-Chousen [Afghanistan: Challenges to Reconstruction and Recovery] (pp205-208 and pp224). Written and edited by K. Mushakoji and Y. Endo. Nihon Keizai Hyouronsha Ltd.

Peshawar-kai Home Page "About us Peshawar-kai". Retrieved from <http://www 1a.biglobe.ne.jp/peshawar/eg/annai.html> on 2016 Feb. 2.

Raphy Favre (2005). Interface between State and Society in Afghanistan: Discussion on Key Social Features affecting Governance, Reconciliation and Reconstruction (pp3-8 and pp12). AIZON, February 2005. Retrieved from <http://www.aizon.org/Administration\%20and\%20society\%20in\%20Afghanistan.pdf>

Roland Paris and Timothy D. Sisk (2009). The Dilemmas of Statebuilding: Confronting the Contradictions of Postwar Peace Operations (pp305-306). ROUTLEDGE.

Takeshi Daimon (2003). Nation Building of Post-Conflict Countries and the Role of Foreign Assistance: Perspectives for Afghan Reconstruction. (pp54-55). International Studies of Meiji Gakuin University 23.

Tetsu Nakamura (2007). Isha-Yosuiro-wo-Hiraku [A Doctor Constructs Irrigation Canals]. (pp179). Sekifusha.

Tetsu Nakamura (2014). V. Evaluation of Project Activities; Annual Report 2014, Rehabilitation of Irrigation System in Kashkot, Sheiwa District.

Tetsu Nakamura (2015). Obtained from the interview to Dr. Tetsu Nakamura on February 2015.

UN Data “Afghanistan”. Retrieved from <http://data.un.org/CountryProfile.aspx> on 2016 Feb. 1. 
UNDP/FAO (1981). Afghanistan National Parks and Wildlife Management: A Contribution to a Conservation Strategy.

Vincent Thomas with Wamiqullah Mumtaz and Mujib Ahmad Azizi (2012). Mind the Gap? : Local practices and institutional reforms for water allocation in Afghanistan's Panj-Amu River Basin. Afghanistan Research and Evaluation Unit (AREU), Case Study Series, June 2012.

Yoshio, E. (2004). Chapter 2 Fukkou-heno-Shakaiteki-Rekishiteki-Kankyo [Social and Historical Environment toward Recovery]; Afuganisutan: Saiken-to-Fukkou-heno-Chousen [Afghanistan: Challenges to Reconstruction and Recovery], 51-56. Written and edited by K. Mushakoji and Y. Endo. Nihon Keizai Hyouronsha Ltd.

Yutaka, H. (2014). A Peacebuilding from the Bottom: Daily Life and Local Governance in Rural Afghanistan. Islam and Civilisational Renewal, 5(3), International Institute of Advanced Islamic Studies (IAIS).

This work is licensed under a Creative Commons Attribution 3.0 License. 